\section{REPORT OF A CASE \\ OF \\ COMPOUND COMMINUTED FRACTURE OF THE TIBIA AND FIBULA.}

\author{
By CHARLES E. CHAPMAN, L.R.C.P.E., Biarritz, \\ LATR SURGBON TO THR VIRGIN GORDA MINING COMPANY, \\ WEST LNDIES.
}

T. $\mathrm{K}-$, a miner from Cornwall, residing in Virgin Gorda, West Indies, a man of average health, and thirty-three years of age, was firing powder from an iron tube on Jan. $13 \mathrm{th}, 1861$, at eleven o'clock A.M., when the tube burst, and he was struck by the fragments and by portions of surrounding loose granite rock. When found, his left leg was lying, from its middle part, doubled on itself, part of the shaft of the tibia protrud. ing, and portions of the tibia and fibula lying near him. His right arm and hand were severely burnt. He replaced the leg in position himself, and was conveyed at once to his house.

I saw him within a quarter of an honr after the accident. The whole middle third of the leg appeared partially disintegrated. Protruding from a large wound were four to five inches in length of the belly of the tibialis anticus muscle. The end of the uppir portion of the shaft of the tibia was perceptible, and the fracture there had been almost transverse; but the end of the lower portion was difficult to distinguish, the bone having been obliquely fracturei at this part. Between these portions appeared a hiatus of tive to six inches; the intervening portion had been splintered longitudinally, and the greater part carried away, whilst a large splinter lay displaced inwards. I did not examine minutely the condition of the fibula; but part of its upper and iniddle thirds were carried away.

Under these circumstances I recommended amputation, especially on account of the heat of the climate-averaging from $84^{\circ} \mathrm{Fahr}$. to $86^{\circ}$ in the shade at noon, and only a few degrees below that at night. As circulation in the foot was perfect, though feeble, I was induced, however, to postpone the operation. I put the leg up lighrly in splints, and applied wet lint to the larce wound in front, and to two smaller wounds in the calf. I then, by means of keeping an almost continual stream of water, squeezed from a large sponge, poured over the whole limb from just below the knee, controlled the temperature of the leg to that of a slight degree more than natural heat. This duty was carefully performed by assistants, and to it I attribute the success of the case. The water was applied almost constantly for the first fortnight or three weeks, and then at intervals whenever the leg showed a tendency to over-action or much pain. The greatest cuution was used in probing or moving the linb; and as the anterior tibial artery lay exposed in the wound, a tourniquet was kept applied over the popliteal artery, but not compressed. 'The arm and hand were dressed with lime-water and linseed-oil liniment.

Jan. 14th. - Circulation in the limb perfect; pulse 85, but quiet; tongue clean. He is cheerful, and takes the low diet allowed well. No action in the leg yet. The burns are much inflamed and painful. In the afternoon he had administered a copious warm water enema, which acted freely on the bowels.

15th. - Feels quite comfortable. Puise 80 , and quiet; tongue clean. There is slight saugniueous discharge from the wound; no pain in the leg. Circulation and temperature good. Ordered to have the enema repeated, and to take a sedative draught at bedtime.

16 th. - He has slept well, and his general health is little disturbed. The wound is begining to discharge a purulent sanies, chiefly from its edges. The larger part of the exposed muscle, which rises about an inch in the middle above the general surface, appears covered with a thin brownish slough. This muscle serves mechanically to fill up and occlucle from access of air much of the lower portion of the wound. Ordered to repeat the enema and draught, and to take two tablespoonfuls of the following mixture every four hours:- Nitrate of potash, one drachm; antimonial wine, two drachms; tincture of henbane, three drachms; spirit of nitrous ether, three drachms; solution of opinm, twenty minims; camphor water, seven ounces.

17th. - He has slept badly, and his tongue is a lintle furred, but the pulse has not risen. The leg is feeling comfortable. A distinct line of demarcation is drawn around the circumference of the exposed muscle, but the sloughing is quite superficial. A little more action is going on in the deeper parts that are exposed; the sanious matter oozing out is more purulent. The bandages and dressings were all removed, and the leg placed on a double inclined wooden splint. The enema and draught were ordered to be repeated.

He was now greatly troubled by the presence of the larvæ of flies crawling about the limb, and even all over bis body, and burrowing in his skin. Chlorinated water, constant washing, and changing the dressing; were of little service. I had recourse then to powdering the wound with calomel, a remedy that instantly drove away or killed them. I had used it for a similar purpose in dressing the wounds of animals. I would recommend its early application as a precautionary measure. Perfect rest was essential to the recovery of this limb; and for three weeks after this the bundages and pals, though constantly saturated with water, were never entirely changed, yet no maggots and little smell were present. I have also to remark, that the use of a sliding board in his couch, with a movable pillow under the nates, allowing of withdrawal without disturbing the body, enabled me to keep the leg and hips in one position without the necessity of tight bandaying. I look upon this arrangement and modifications of it as far preferable to the use of the bed-pan, which always causes pain and movement, and it is chenp and readily procurable in most places.

19 th. - He passed a barl night, and to.day is somewhat ex. hausted; pulse fallen to 70 , and tongue slightly furred. During the day the Pharmacopcial cataplasma carbonis was applied to the wound for an conple of hours to clean the sloughing parts; but this excited intense action, and caused the whole limb to contract spasmor? ically, and the wound to pulsate violently. Im. mediately on seeing him I re-applied the wet lint and assiduous douching. To repeat the enema and anodyne draught, with eighty drops of the liquor of opium.

$22 \mathrm{nd}$. - The general health good; the burns of the arm and havd healed; the wound discharging now about two ounces of healthy pus daily. About an inch of the upper part of the tibia remaining is lying exposed at the bottom of the wound. Small fragments of granite and bone are discharged from the deener parts.

24th. - General health excellent; continues to take the draught at night and the mixture occasionaliy, but has left off the enemata, as the bowels act naturally; wound cleaning, and the leg quite easy. Applied adhesive plaster round the wounded part of the limb, and tightened the bandages.

$27 \mathrm{th}$. - The ulceration around the exposed part of the tibia slightly spreading. The wound is still discharging about two ounces of pus daily, a quantity which was never exceeded in this case owing to the constant application of the cold water keeping under both local and generial action; and this drain on the system was easily borne witb little assistance from stimulants, and no appearance of hectic. I have seen four times that amount or more discharged from a less serious wound under the application of light wet-lint and gutta-percha dressings. He was ordered a little chicken to-day.

31 st. - A little excited; some bleeding from the deeper parts, and pulsation of anterior tibial more forcible. Ordered, perfect quiets, sedatives, and assiduous douching.

Feb. 4th.- General health excellent; wound looking clean, and granulations springing up around exposed part of tibia; less swelling of leg, and fleshy parts firmer.

9 th. - Put the leg up in gutta-percha splints and on pillows to relieve the heel, on which is a small slough; the leg is shortened about one inch; granulations have covered the exposed bone.

14th. - Strength somewhat failing; leg doing well; deep parts filling up, and skin shooting over the exposed muscle; less discharge and swelling daily; the knee is rotated too much outwards, but $I$ will not risk the breaking up of adhesions necessary to replace it. The douching has been discontinued for two days now. Ordered one glass of beer daily, and to take quinine mix ture and meat diet.

$20 \mathrm{ch} .-\mathrm{He}$ is out of danger now, and his general health is good; the wound discharges scarcely one ounce of pus daily the exposed muscle is nearly cicatrized, and the parts are feeling solid and firm; union has apparently partially taken place between the upper part of the tibia and the displaced longitudinal fragment mentioned above.

26 th. - He was moved on a couch into the open air.

March 14th. - The leg was put up in a starch bandage, and in a day or so he could more about on crutches.

A pril 29th. - He went to work as an engine-man, and with one short interval has continued at work since.

In June, a piece of the longitudinal fragment of the tibia, about an inch and a half in length, came away, and arter this all the sinuses dried up. He is now (Argust, 1861) perfectly 
recovered, and can walk without inconvenience. The leg is nearly as strong as the right. Dense masses of bone fill up the interval of from five to six inches the removed bone left. The leg is shortened by about three quarters of an inch, but is natural in appearance, with the exception of the knee being a little too much rotated outwards, some bulging at the middle third, and the slightly depressed cicatrices in front.

In conclusion I would remark, that I attribute this re. covery almost entirely to the suppression of undue inflam. matory action by the cold water douching; also to careful attention being paid to the constitution, especially avoiding disturbance to the dig-stive organs by purgatives; and to perfect rest and non-interference as regards the limb by too much probing, handling, dressing, bandaging, or movement of the body.

Biarritz, 1863.

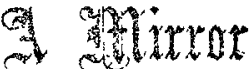

OF THE PRACTIOE OF

\section{MEDICINE AND SURGERY IN THE}

\section{HOSPITALS OF LONDON.}

Nulla est alia pro certo noscendi via, nisi quam plurimas et morborum et dissectionum historias, tam aliorum proprias, collectas habere et inter so comparare.-MoresenI. De Sed.et Caus. Morb., lib. 14. Procmiam.

\section{WESTMINSTER HOSPITAL.}

CLOSURE OF THE JAWS BY RIGID CICATRICES AND BY A BRIDGE OF BONE; INTERNAL DIVISION, AND SUBSEQUENT TREATMENT BY SHLVER CAPS AND SHIELDS AFFIXED TO THE TEETH.

(Under the care of Mr. BARNARd HoLT.)

IN The LANCET of Oct. 25th, 1862, we recorded an example of closure of the jaws from cicatrices successfully treated in this hospital by Mr. Heath, who removed a portion of the lower jaw and formed a false joint in the manner proposed by Professor Esmarch. To-day we record a somewhat similar case treated in the same hospital by $\mathbf{M r}$. Holt, by incisions within the mouth, and subsequently by metal shields adapted to the teeth, the result of which has been effectually to provent reunion of the cheek and gums, and to give the patient a most satisfactory amount of movement of the jaw.

Frances $\mathrm{H}-$, aged seventeen, was admitted July 3rd, 1862, suffering from closure of the jaws. In 1857 the patient had fever, attended with an abscess in the cheek on the right side, which led to such contraction and adhesion of the mucons membrane to the jaw as to cause great difficulty in opening the mouth. This difficulty continued to increase, and attempts were made, by direction of the surgeon under whose charge she was, to force open the mouth with a spoon-frequently used, but to no purpose. Early in March, 1859, she had scarles fever very slightly; and in the following August she was sent to the Kent and Canterbury Hospital, where several of her teeth were extracted, and an iron screw was used to force open the mouth, but without permanent benetit. On Nov. $29 \mathrm{ih}, 1860$, she was admitted into the Westminster Hospital, when Mr. Holt divided the bands of cicatrix within the cheek freely, and by careful dressing she obtained some power over the jaw, and was discharged in January, 1861.

On being again admitted July 3 rd, 1862 , she presented the following condition:- The mouth is contracted on the right side, but not sufficiently to prevent the lips from opening to expose the front teeth. The jaws are firmly closed, the upper overlapping the lower incisors in the ordinary way, allowing a space of one-sixteenth of an inch between them, through which food is introduced. The right cheek is very dense and rigid, and there is a considerable depression in it. The finger camnot be introduced beyond the canine teeth, owing to the firm adhesions of the cheek to the gums; while on the left side the mucous membrane of the cheek is free and healthy. The patient's general health is good, as she takes sufficient food, although slowly.

Seeing the amount of deformity which resulted from Esmarch' operation in Mr. Heath's case, although in other respects $\mathrm{v}$ ery satisfactory, Mr. Holt greferred and deternined to adopt the plan proposed and successfully carried out by $\mathrm{Mr}$. Clendon, dental surgeon to the hospital, in a case under the care of the late Mr. B. Phillips, and also in another of his own in private practice-namely, to operate from the front of the mouth, to separate the cheek freely from all adbesions, and employ mechanical means to prevent the possibility of their reunion.

The operation was performed on the 23rd of July. The patient having been placed nnder chloroform, Mr. Holt divided the cicatrices freely within the mouth, separating the cheek from the upper and lower jaws until the finger reached well back to the ramus of the jaw. When this had been effected the jaw still remained fixed, and it was found that the teeth of the lower jaw, from the hicuspids backwards, had been thrust inwards, and that from the outer margin of the alveolus in this region a firm plate of bone extended to the alveolus of the upper jaw, and effectually prevented any movement. With a narrow saw introduced into the mouth, Mr. Holt succeeded in dividing this, and the mouth could then be opened, after which the remains of the ridge were removed with tie bone-forceps. The cheek was stuffed with oiled lint to prevent the recurrence of the adhesions, and the patient was put to bed.

July 25th. - There was considerable swelling of the face; the lint was therefore removed, and the finger passed freely in every direction; after which the lint was replaced.

$28 \mathrm{th}$. - The swelling of the face having somewhat subsided, Mr. Clendon took wax and gutta-percha impressions of the month, under chloroform, in order to form the shields to be attached to the teeth and inserted between the cheek and gums.

30th. - The shields were fitted. They consist of a horizontal portion fitting upon the molar teeth, and fastened with bands to the canine and incisor teeth, and a vertical portion which passes by the side of the alveolus to the bottom of the sulcus between it and the cheek. The edge of this is quite thin, and

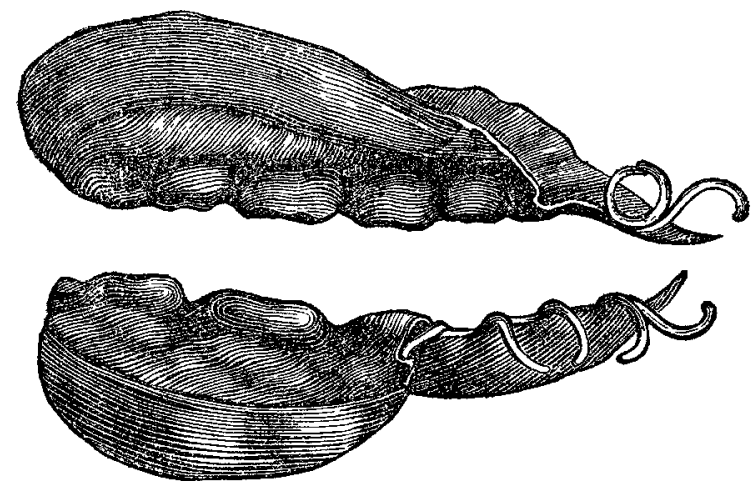

serves to cut a groove in the adhesions which are already beginning to fill up the space.

Aug. 7th. - The shields keep thoroughly in their places; but as the cheek is stili raw, wet lint is inserted between the gams and the lining of the cheek, and the finger is daily passed freely beneath the cheek to the full extent of the teeth. Two wedges of wood were fitted to the mouth, one on each side, so as to maintain the constant separation of the jaws.

$15 \mathrm{th}$. The condition of the mouth is in every way satisfactory ; the gums and cheek are beginning to be covered with mucous membrane, and the discharge is slight. A band in the middle of the cheek having become racher tense and prominent, it was freely cauterized with nitrate of silver.

Sept. 1st. - The shields and wedges are worn without discomfort, and the girl can open her mouth most satisfactorily. The shields effectually prevent adhesious forming between the gum and the chesk.

From this time the patient's progress was uninterrupted. She recovered perfect use of her jaw and mouth, and all tendency to recontraction seemed to have disappeared. The girl was kept under observation at the hospital many weeks longer than was absolutely necessary for the further carrying out of the treatment, with the view of testing the permanence of the cure, and was finally sent into the country on November lst, 1862 , with the shields still in the mouth, and still wearing one of the wedges, which she had become quite accustomed to.

She returned to the hospital for a few days in December that the progress might be noted, and the accompanying portrait (from a photograph) was then taken for the sake of comparison with that given in THe LANCeT of Oet. $25 \mathrm{ch}, 1862$, p. 444, showing the result of Esmarch's operation. The shields were removed for five days in order to be sketched, and no apparent change resulted from their non-use; but, for the sake of safety, 